\title{
A RACIONALIZAÇÃO DO ESPAÇO COMO DISPOSITIVO DA EDUCAÇÃO SUPERIOR
}

\author{
RATIONALIZATION OF SPACE AS A DEVICE FOR HIGHER EDUCATION
}

\author{
LA RACIONALIZACIÓN DEL ESPACIO COMO DISPOSITIVO DE LA EDUCACIÓN \\ SUPERIOR
}

\author{
Mário Luiz Ferrari Nunes*, Marcos Garcia Neira**
}

Palavras chave:

Currículo.

Educação Física.

Educação Superior.

Racionalização.

\begin{abstract}
Resumo: Este artigo destaca a racionalização do espaço como elemento significativo da Educação Superior a partir do currículo de um curso de Licenciatura em Educação Física de uma instituição privada de ensino. Por transmitir significados, determinar e separar os locais nos quais os indivíduos circulam e convivem, nele se produzem discursos e práticas culturais que introduzem novas formas de regulação dos sujeitos, constituindo estratégias de subjetivação. Os dados produzidos por meio de observações sistemáticas foram analisados mediante a noção de governamentalidade, entendida por Michel Foucault como a arte de governo de si e dos outros. Os resultados indicam que são realizados investimentos estratégicos em práticas culturais específicas com a finalidade de regular e validar formas de viver afeitas a algumas características do neoliberalismo globalizado como consumismo, espetáculo e volatilidade.
\end{abstract}

Keywords:

Curriculum.

Physical Education.

Education, higher.

Rationalization.

Abstract: This article discusses rationalization of space as a meaningful element for higher education on the Physical Education curriculum of a private school. Since it conveys meaning and determines and separates the places where people live and circulate, discourses and cultural practices are produced in it that introduce new forms for regulating subjects, which constitute subjectivation strategies. Data produced by systematic observations were analyzed under the notion of governmentality, understood by Michel Foucault as the art of governing self and others. The results indicate that strategic investments are made in specific cultural practices in order to regulate and validate forms of living that are close to some features of globalized neoliberalism such as consumerism, spectacle and volatility.

Palabras clave: Currículo.

Educación Física. Educación Superior. Racionalización. y separar los locales donde circulan y conviven los individuos, en él se producen
Resumen: En este artículo se destaca la racionalización del espacio como elemento significativo de la Educación Superior a partir del currículo de un curso de licenciatura en Educación Física de una institución privada. Por transmitir significados, determinar discursos y prácticas culturales que introducen nuevas formas de regulación de los sujetos, constituyendo estrategias de subjetivación. Los datos producidos a través de observaciones sistemáticas fueron analizados mediante la noción de gubernamentalidad, entendida por Michel Foucault como el arte de gobierno de sí y de los otros. Los resultados indican que se realizan inversiones estratégicas en prácticas culturales específicas con el fin de regular y validar formas de vida similares a algunas características del neoliberalismo globalizado, como consumismo, espectáculo y volatilidad.
*Universidade de Campinas. Campinas, SP, Brasil. E-mail: mario.nunes@fef.unicamp.br

**Universidade de São Paulo. São Paulo, SP, Brasil. E-mail: mgneira@usp.br

Recebido em: 27-06-2016 Aprovado em: 27-07-2017

(c) (1) (8) Licence 


\section{PARA COMEÇO DE CONVERSA}

Tornou-se lugar-comum afirmar que vivemos uma época de revolução econômica, cultural e política provocada pela globalização e pela hegemonia do neoliberalismo. Diante desse quadro, Ball (2004) afirma que não há como negar que existem novas formas de controle e regulação da vida privada e que elas operam a construção do sujeito ideal para compor a sociedade globalizada.

Em termos educacionais, o que se espera é a preparação de sujeitos para atuarem em um mercado de trabalho instável, desenvolverem a todo o momento novas habilidades e que sejam flexíveis para se adaptarem e, portanto, mudarem de emprego sempre que necessário (BURBULES; TORRES, 2004). Não é só isso. O sujeito tem que aprender a investir constantemente em si mesmo, valorizando o descarte, logo o consumo, as conquistas e 0 mérito individual (BAUMAN, 2008).

Frente a essas metas, o Ensino Superior (ES) também se modifica. Assistimos ao grande avanço nesse nível de ensino de entidades privadas com fins lucrativos. Como efeito, a cultura empresarial tem regulado e direcionado tanto sua estrutura como a produção científica. Faz-se crer que o conhecimento parece cada vez mais uma mercadoria do que um instrumento de desenvolvimento social, econômico e cultural comum e de direito de todos.

O quadro de análise se amplia diante das pressões internacionais e locais para a inserção de sujeitos das classes populares no ES. De um lado, os movimentos sociais conclamam por melhoria das condições de vida que a formação superior pode proporcionar. Do outro, organizações multilaterais, como o Fundo Monetário Internacional e o Banco Mundial, influenciam as políticas curriculares nos países em desenvolvimento, a fim de formar uma mão de obra que atenda às intenções do capital. Como em muitas áreas, na Educação Física (EF) o resultado tem sido o aumento significativo da presença no ES privado de população outrora ausente da universidade, associado a uma formação superficial e pragmática que, sugestivamente, incentiva ao consumo de novos cursos de capacitação, gerando uma inclusão excludente (NUNES; NEIRA, 2014).

0 neoliberalismo pode ser visto de várias maneiras. Aqui o tratamos nos moldes foucaultianos, ou seja, como arte de governo. Para Foucault (2008a), ao contrário do liberalismo, que tinha horror ao Estado por impor condições de governo à sociedade que não atendiam a critérios econômicos, o neoliberalismo celebra o Estado, pois o coloca a serviço do mercado. Entende-se que é o Estado quem garante as melhores condições para o desenvolvimento do capital. Para imperar, o neoliberalismo transpõe a racionalidade característica do setor econômico para qualquer lugar onde se possam gerar riquezas. Para tanto é necessário promover novas tecnologias de subjetivação para que um novo sujeito surja. Um sujeito pensado como livre e autônomo para fazer suas próprias escolhas, mas, que, no fundo, é moldável e governado para fazer apenas as escolhas que se quer que ele faça e com isso garantir a eficácia e a funcionalidade do capitalismo.

Em tempos de globalização e da reformulação do Estado, o currículo do ES é de vital importância para o desenvolvimento econômico das nações. Afinal, atua na formação daqueles que devem garantir a articulação entre os sistemas educativos e a produtividade do mercado. Por conta disso, o currículo tem uma posição estratégica nas reformas educacionais e sociais, pois é por meio dele que seus sujeitos são normalizados em meio a um longo período de 
vivências em certo regime de verdade. Não à toa, o currículo regula não somente o que é compreendido em termos cognitivos, mas a maneira como a cognição produz sensibilidades, disposições e consciência do mundo social (POPKEWITZ, 1995).

Dentre as diversas definições do que venha a ser currículo, adotamos a concepção de Moreira (2006), que o define como conjunto de experiências vivenciadas pelos estudantes no seu percurso formativo sob a orientação das instituições de ensino, como também 0 próprio ambiente em ação. $O$ currículo é mais do que um espaço-tempo em que se distribuem disciplinas e se transmitem conhecimentos. Nele, seus sujeitos têm experiências diversas nas quais acessam conhecimentos, desenvolvem habilidades e comportamentos, mesclando essas aprendizagens com seus modos particulares de ser. Ou seja, a concepção de currículo aqui apresentada inclui todas as formas de organização do espaço, do tempo, dos conhecimentos, das verdades e das práticas que ocorrem no interior do ES. Elementos que têm história e passam por critérios de seleção a fim de garantir a sua eficácia.

Veiga-Neto (2000) explica que o currículo não é o que possibilita o desenvolvimento e o aperfeiçoamento da racionalidade, nem a emancipação do indivíduo. Tampouco pode ser analisado a partir de princípios intelectuais e padrões morais, fundados nas filosofias da consciência, que historicamente tentam moldar os sujeitos. Sua análise deve ser feita questionando o porquê e como suas práticas se modificam e, principalmente, quais são as novas práticas que estão surgindo e quais relações que estabelecem com os novos dispositivos que posicionam os sujeitos em função do neoliberalismo e de uma cultura globalizada.

Diante desse quadro, neste artigo, focamos um aspecto que marca o currículo do curso de Licenciatura em EF em uma Instituição de Ensino Superior privado (IES). O mote central é problematizar como a racionalização do espaço assume o caráter de um dispositivo pedagógico do currículo, considerando os modos de organização, a distribuição do tempo, a arquitetura e a promoção de práticas culturais com finalidades distintas, que funcionam como formas de conduzir as condutas dos sujeitos que nele adentram e se subjetivam. Trata-se de investigar como os sujeitos são pensados para tornarem-se agentes e parceiros do mercado.

\section{ESTREITANDO A CONVERSA: A GOVERNAMENTALIDADE}

A noção de governamentalidade desenvolvida por Foucault (2008b) ajuda-nos a compreender as mudanças que ocorrem nas formas de governo das populações e dos sujeitos. O neologismo serve para descrever a arte de governar e indicar o surgimento de modelos distintos de regimes de administração a partir do século XVI, que se tornaram a base da política liberal e da modernidade. Seu interesse foi o de analisar o exercício do poder, atendo-se ao desenvolvimento das racionalidades e tecnologias governamentais, que regulam as ações dos sujeitos, e à imanência das práticas a ele relacionadas. Cabe destacarmos aqui a noção de poder formulada por Foucault.

O poder deve ser analisado como algo que circula, ou melhor, como algo que só funciona em cadeia. Nunca está localizado aqui e ali, nunca está nas mãos de alguns, nunca é apropriado como uma riqueza ou um bem. 0 poder funciona e se exerce em rede. Nas suas malhas os indivíduos não só circulam mas estão sempre em posição de exercer este poder e de sofrer sua ação; nunca são 0 alvo inerte ou consentido do poder, são sempre centros de transmissão. Em outros termos, 0 poder não se aplica aos indivíduos, passa por eles (FOUCAULT, 1992a, p. 183). 
Para Foucault (2008b), o nascimento do Estado moderno está relacionado a uma crise do poder soberano quanto às formas de governar, momento em que a preocupação do Estado deixa de ser 0 controle do território e passa para o controle da população. Com 0 aumento da massa urbana, a crescente divisão do trabalho, as formas de produção capitalista assentadas nas noções de acumulação e propriedade e a organização dos Estados nacionais, emergiram novos modos de ver e diferenciar indivíduos e populações. Os problemas de governo multiplicaram-se e espraiaram-se em várias direções. Em suma, a razão do Estado e a preocupação com a população ocasionaram uma explosão do interesse na "arte de governar", motivadas por questões diversas: o governo de si (a conduta pessoal), o governo de almas (tema da doutrina pastoral) e o governo das crianças (a problemática da pedagogia) (FOUCAULT, 2008b).

Apesar de a noção de governo estar comumente relacionada ao domínio político, não se trata de um grupo de pessoas que de forma burocrática atua à frente da gestão daquilo que é público. $O$ governo é entendido como relação entre sujeitos e como relação do sujeito para consigo mesmo. É a "condução das condutas", congregando procedimentos, técnicas, invenções, cálculos, instituições e ideias propositalmente mobilizadas para influenciar a conduta dos outros. São as relações entre as pessoas que as estimulam a agir. Isso quer dizer que as pessoas não controlam seus comportamentos em função de uma autonomia que thes é própria ou desenvolvida, mas, sim, porque suas formas de ser constituíram-se mediante um amplo movimento histórico, político e cultural no qual um ser humano torna-se sujeito.

A visão do filósofo evita a questão da análise do sujeito sempre submetido à lei, se possui ou não possui direitos. Esse pressuposto impediria colocar a autoconstituição ética do sujeito em jogos de liberdade. A governamentalidade se refere ao conjunto de práticas e estratégias que os indivíduos livres utilizam para governar a si e o outro. Trata da intersecção das tecnologias de si e das tecnologias de dominação. Para Foucault, a família, o local de trabalho, a profissão, a população e a escola são apenas alguns dos muitos lugares nos quais a operação de governar 0 outro e a si mesmo acontece. Isso implica a questão de como o poder é exercido.

A efetivação desse governo de si ou dos outros se dá a partir do momento em que os sujeitos orientam suas ações e compreendem a existência da liberdade com a qual podem agir, fazendo dessa liberdade tanto um instrumento como um efeito. A governamentalidade nos leva a ver que as pessoas não são incorporadas ou ajustadas ao Estado moderno por meio da força ou tutela. É a governamentalização da sua liberdade que possibilita a sua inclusão no Estado governamental.

As sociedades modernas podem ser definidas pela preocupação tanto com as formas de exercício da liberdade dos indivíduos, cada qual com suas singularidades, como com o mundo em que atuam. Para garantir essas relações, o bom governamento é aquele que governa economicamente, procurando obter maiores resultados com mínimo esforço tanto no que se refere às questões econômicas, como também em relação ao tempo, afetos, prazer e felicidade (VEIGA-NETO, 2000). Nessa articulação, o Estado passa a operar com uma dinâmica que absorve para si as relações entre os indivíduos e as estruturas sociais mais amplas, de tal modo que essas relações não fiquem sob o controle dos indivíduos, mas de experts. Nesse jogo, as experiências subjetivas são modeladas de tal forma que parecem pertencer aos próprios sujeitos, que somente podem atuar diante daquilo que é dito sobre eles. Em termos práticos, um professor de Educação Física somente se governa diante daquilo que 
é produzido e determina o que ele é, o que deve fazer e, principalmente, o modo como deve governar os alunos.

Ao longo das primeiras décadas do século XX, a excessiva regulação estatal, tanto nos regimes totalitários como nas democracias mais abertas, foi vista como dispendiosa. Emergiram críticas também ao Estado por conta dos gastos sociais, necessários para o controle da população. Diante dos princípios da acumulação capitalista, entendia-se que o setor produtivo deveria gerar riquezas e não sustentar os custos das políticas públicas de previdência social. Do mesmo modo, o caráter de intervenção do Estado na economia do mercado foi visto como empecilho ao crescimento das empresas. Emerge, então, a necessidade de outra forma de governo das populações: o neoliberalismo.

A arte de governar neoliberal pressupõe a criação de condições por parte do Estado que permitam a liberdade empresarial do sujeito em um ambiente de mercado, que reforça aspectos individuais e competitivos. Alerta Foucault (2008a) que a grade de inteligibilidade adotada para o comportamento desse novo sujeito é a econômica. Nela, o sujeito só será governável na medida em que atuar em conformidade com os seus interesses. Foucault (2004) explica que a liberdade do sujeito é a sua condição de existência, assim como a do poder, logo da sujeição, pois para ocorrer o exercício da autoridade se necessita de um sujeito de desejos, interesses e direitos. A sujeição é a condição para que o sujeito possa agir livremente, pois, antes de tudo, ele tem que ser produzido, guiado para poder ser alguém capaz de exercer sua liberdade em meio às tramas dos sistemas de dominação.

Para Veiga-Neto e Saraiva (2011), a governamentalidade, como uma ferramenta analítica, possibilita compreender melhor a razão que levou os Estados modernos a fazerem da educação uma instituição privilegiada para a formação de sujeitos, atentando ao estabelecimento de seus objetivos, métodos e de suas formas de funcionamento. Neste estudo, interessaramnos as técnicas de dominação: os discursos e as práticas discursivas que visam capturar os sujeitos do currículo e introduzi-los na sociedade que se pretende neoliberal.

\section{O DEBATE: A RACIONALIZAÇÃO DO ESPAÇO}

Como qualquer instituição social, a IES lócus desta pesquisa apresenta algumas características particulares e outras comuns que atuam sobre as formas de regulação dos sujeitos. Seus alunos são os representantes das classes sociais C, D e E, aqueles que compõem a maior demanda por vagas no ES. Está situada em uma grande metrópole do país, em um dos bairros que vêm passando por modificações decorrentes da substituição do setor industrial pelo de serviços. Isso fez com que grandes áreas da região se transformassem por completo. Surgiram condomínios, centros empresariais e de convenções, hotéis, casas de espetáculos e eventos. Mudanças urbanas que possibilitaram a expansão física e das matrículas da instituição.

O campus tem excelente infraestrutura e área verde privilegiada. No seu portal da internet, as imagens do espaço físico e das instalações são colocadas em primeiro plano, deixando em segundo os links de acesso às informações institucionais. Os encartes informativos apresentam fotos dos espaços, meticulosamente elaboradas e selecionadas. No caso do portal, os efeitos especiais das trocas constantes de imagens detalham a criatividade de seus mentores. Sem dúvida, trata-se de formas de anúncio comercial que realçam a 
espetaculosidade que a publicidade destes tempos exige e, naturalmente, são encampadas pela educação.

O privilégio dado ao seu espaço físico no portal pode ser compreendido como marca institucional. Essa exposição não é à toa, ela é produzida de modo a garantir a sedução e a conquista de consumidores. Como explanam Lipovetsky e Serroy (2011), as marcas constituem o grande capital das empresas e se caracterizam como um novo elemento cultural em tempos de globalização. Ao deixar em abas de acesso laterais as questões referentes ao conhecimento, aos aspectos contratuais e financeiros, a instituição demonstra que a publicidade em cena se constitui em um valor estético. Indica a perda da importância do valor do conhecimento, e o predomínio da lógica comercial e publicitária. Ação que reforça na sociedade de consumo a necessidade da cultura de marcas em um mundo saturado por logotipos.

A cultura de marcas está em todo lugar. Na entrada no campus há um pórtico imponente. São duas colunas que representam o logo institucional e significam a aproximação do aluno ao conhecimento. Ao adentrarem seu espaço interior, as pessoas se deparam com alamedas arborizadas, jardins, quiosques, uma pequena queda d'água artificial, que segue um curso entre pedras ornamentais. É possível observar a presença de alguns pássaros e símios característicos da mata atlântica. À noite, as árvores recebem iluminação especial, instaurando a sensação de estar em um ambiente tropical.

Em meio ao verde, há um oratório católico, que reforça determinada identidade em meio à diversidade cultural, que caracteriza seu público. Ao longo do espaço, há lugares estratégicos para estudo e encontros. Esses se estruturam com mesas e bancos de madeira para grupos de seis a oito pessoas, com iluminação focal e aquecedores a gás. Um xadrez gigante cercado por arquibancadas de madeira e lamparinas em formatos de tochas marca outro espaço. Destacam-se ainda a pequena concha acústica para apresentações artísticas, três praças de alimentação e uma fonte com iluminação especial. No entorno da área central encontram-se: uma agência bancária; lojas de roupas e acessórios com a marca da instituição; dois laboratórios de informática; a clínica de fisioterapia que presta serviços à comunidade; várias salas de aula, com as janelas voltadas para o espaço verde; a central de atendimento ao aluno, com seu imponente lustre de cristais, instalada no térreo de um prédio, cuja frente é toda envidraçada e contém o logo institucional. A piscina semiolímpica aberta e aquecida, também iluminada, e o amplo e equipado teatro, decorado com pedras de granito, completam a cena de um lugar aprazível de estar. Tudo e todos posicionados sob os olhares atentos de câmeras de vigilância.

O curso de EF também é privilegiado. Além da piscina, dispõe de laboratórios; salas para atividades rítmicas e artes marciais; ginásio poliesportivo coberto, com arquibancada, placar eletrônico e sistema de som; pista de atletismo, iluminada com lâmpadas de LED instaladas ao rés do chão; academia-escola equipada com equipamentos de musculação, de atividades aeróbias e de ginástica acrobática, além de ampla disponibilidade de assessórios para as atividades esportivas.

Para Foucault (1992b), desde o final do século XVIII, a arquitetura se articula com os problemas do crescimento urbano. Para ele, antes desse período, as edificações, como fortalezas e castelos, manifestavam o poder. A partir do período citado, ela é utilizada para resolver problemas do espaço em relação ao crescimento da população, tencionando objetivos políticos e econômicos. Ela se torna uma forma de exercício de poder. 
A arquitetura e as demais instalações de qualquer construção podem remeter à ideia de moderno ou ultrapassado, de agradável ou desagradável, de abandono ou cuidado, entre tantas. Ou seja, podem produzir distintas significações. Ao elaborar espaços e dispor objetos, a arquitetura de um lugar pode instituir, pela sua materialidade, representações que determinam relações de uso, de permanência e circulação de indivíduos e grupos, criando hábitos e veiculando/interditando práticas e discursos. Em suma, as práticas de uma dada cultura também sofrem intercorrências da arquitetura do lugar e do modo como seu espaço é otimizado. Com isso, as relações sociais presentes em espaços diversos classificam, hierarquizam e selecionam sujeitos, gestos e modos de ser. Ela transmite significados em meio aos discursos saturados por poder e possibilita práticas que regulam as ações dos sujeitos.

A utilização do espaço do campus é planejada para o desenvolvimento de um sem-número de práticas sociais promovidas pela instituição, como: homenagens a atletasestudantes subsidiados que venceram competições, shows de variados gêneros musicais, peças de teatro, desfile de escola de samba, rodas de capoeira, paredes de escalada, trampolim acrobático, atividades circenses, campeonatos de lutas e vários esportes, promoção de produtos comerciais em estandes de empresas que visam ao público estudantil e outros eventos. Tudo isso frequentado aleatoriamente por verdadeiros enxames.

Bauman (2008) explica que nestes tempos o enxame tende a substituir o grupo. No enxame não há lideres, hierarquia de autoridade e estrutura de poder. Seus membros se reúnem, se dispersam e se juntam novamente de uma ocasião para outra, por motivos diferentes e atraídos por alvos mutáveis. É um agregado de unidades que reproduzem padrões de comportamento semelhantes em torno do mesmo fim com a sensação de que escolheram suas opções livremente. A profusão de ofertas lúdicas em tempos e horários variados tende a fragilizar grupos, atraindo e dissolvendo rapidamente os enxames interessados em coisas variadas.

Os espaços planejados surpreendem pela sua proposta com ares de informalidade e descontração. No entanto, isso não é surpresa, pois esse movimento está presente em diversas empresas. Hoje é comum o investimento na produção de salas temáticas direcionadas às reuniões, recantos paradisíacos para a alimentação, espaços agradáveis para acolher os interessados em seu produto, áreas apropriadas para o lazer, atividade física em geral, descanso, jogos, massagens etc. Assim como vem acontecendo nas empresas, no currículo investigado fica impossível fazer distinção entre os diversos objetivos dos espaços, pois, por lá, os sujeitos trabalham, produzem, estudam e também desfrutam de momentos de lazer.

Como se nota, os espaços urbanos de socialização e produção de cultura estão cada vez mais privatizados. Os poucos restantes estão em vias de transformar-se em espaços de exclusão social, restando os institucionais como lócus de produção de cultura e modos de ser. Diante de uma população diretamente afetada por essa condição e do aumento da concorrência, a instituição investigada não somente agrega valores positivos à sua marca pelo fomento à cultura. Com essa ação, ela naturaliza a estratégia da responsabilidade social promovida pelas entidades empresariais, que visam à renúncia fiscal. Além disso, a instituição contribui para convencer seu público quanto à desresponsabilização do Estado para exercer essa função, reforçando aspectos da governamentalidade neoliberal.

Outro detalhe merece análise: parcela das atividades mencionadas ocorre simultaneamente às aulas. Fundem-se intenções e temporalidades distintas, ocasionando, 
para alguns, sinais de perigo para com a atividade-fim da IES e, para outros, momentos de descontração em um ambiente historicamente marcado pela rigidez. 0 que se vê é a transformação da cultura em negócio e do negócio em cultura. Uma cultura que exalta os prazeres do bem-estar, entretenimento, espetáculo, gozo sensorial, deleite do ócio e não mais os ideais de sacrifício (LIPOVETSKY, 2012), que marcavam os discursos das conquistas acadêmicas.

O negócio como cultura faz coabitar na IES artefatos e identidades culturais distintos. A racionalização do espaço torna-o multicultural por excelência, pois nele todos os estilos podem circular e se expressar. 0 currículo em questão dá andamento ao hibridismo entre o global e o local, entre o regional e o cosmopolita. Se, por um lado, esse processo evita a temida homogeneização cultural, por outro, esses fluxos de práticas culturais criam possibilidades de identidades partilhadas como consumidores para os mesmos bens, clientes para os mesmos serviços e público para as mesmas mensagens e imagens (HALL, 2003, p. 74).

Esses aspectos remetem à utilização dos espaços pelos cursos, visto que é rigidamente controlada. Isso se destaca no curso de EF. O ginásio muitas vezes acolhe eventos de outros cursos e até de entidades externas, ficando indisponível para as aulas regulares. 0 teatro tem poucas vagas na agenda, pois é uma fonte de recursos financeiros através da locação para eventos diversos. Para a utilização dos demais espaços citados, há necessidade de consulta aos setores administrativos, reforçando o gerencialismo destes tempos. Quando não é possível a utilização, os professores ministram aulas em sala, determinando esse tempo como aula teórica. O que tudo isso pode ensinar para futuros professores que atuarão na educação básica? Onde, exceção a poucas escolas privadas, se disponibiliza tal estrutura? A denominada aula teórica somente pode acontecer quando não há condições para as chamadas aulas práticas? Além disso, qual é a prioridade?

Para Ball (2004), os problemas da concorrência gerados pela cultura da performatividade fazem com que as instituições se preocupem cada vez mais com seu estilo, sua imagem e a maneira como apresentam e organizam as coisas do que com os modos que a fazem operar. De fato, o investimento em tempo, dinheiro e energia com a gestão das aparências, a elaboração das estratégias de marketing e sua efetivação produzem maior opacidade sobre as intenções planejadas. Os aspectos físicos presentes nas instituições educacionais e seus usos transmitem significados às vezes mais fortes do que os conteúdos apresentados por professores ou materiais didáticos.

Os estudos de Sales e Passos (2008) demonstram que as aparências dos prédios escolares suscitam representações de qualidade para quem passa em frente ou frequenta esses espaços. A qualidade da estrutura física denota outros indicadores, como professores bem remunerados, formação humanista, modernidade, cuidado com o meio ambiente. A lógica apresentada pelos seus entrevistados é que se há cuidado com o ambiente, também há com os demais itens da instituição. E isso não é diferente na instituição que acolheu o estudo, como pode ser observado pelos comentários proferidos por alguns alunos, divulgados na rede social da IES, em relação à acolhida aos alunos novos: "Ao entrar aqui, notamos que o [...] preserva e valoriza o meio ambiente. Também acho o projeto deste campus muito interessante, me faz pensar em estudar com qualidade de vida".

A arquitetura, enquanto um acontecimento discursivo, estabelece relações de pertença para sujeitos e formas de vivência estética, que se instalam e se institucionalizam como experiências legítimas. Como identificação de qualidade, a racionalização do espaço traz 
consigo o sentimento de pertencimento à instituição. Esse sentimento é fomentado com a intenção de salvaguardar uma relação duradoura e confiável entre a instituição e seus alunos, maximizando interesses que envolvam afeto e economia. Isso significa o cuidado em manter esse relacionamento. Ao mesmo tempo, para os alunos o espaço pode representar, além do investimento em uma formação superior de qualidade e potencialmente promissora, um percurso da vida permeado pelo prazer e o reconhecimento. 0 resultado dessa operação se obtém com a fórmula que produza melhores resultados para ambos, tanto em termos profissionais e financeiros, como em termos de satisfação e expectativa de viver melhor.

$O[. .$.$] trabalha de forma diferenciada e incentiva o uso de meio de transporte sem$ poluente, disponibilizando em sua unidade estacionamento gratuito para bicicletas. Você que mora próx [sic] ou em locais de fácil acesso poderá substituir seu meio de transporte convencional por bicicleta e economizar com estacionamento e transporte. Faça as contas 1 mês indo de bicicleta equivale a redução do custo universitário e reduz em $70 \%$ a possibilidade de abandono do curso por questões financeiras, além de proteger contra várias doenças, realizar exercício físico diário e não se estressar com 0 trânsito da cidade. [...] Viva o bem-estar, livre-se do trânsito e curta a natureza (comentário de aluno divulgado na rede social da IES).

Nesse bojo, os estudos realizados com o intuito de captar e manter alunos indicam que a relação ambiente/clima é citada como um dos aspectos favoráveis e diferenciais da instituição. Revelam que o espaço físico agradável transmite aos alunos a sensação de estarem em um espaço acolhedor e em um clima de convivência. Tudo isso reforça um ambiente de confiança, pois, mesmo alguns estudantes revelando perceber a intenção de cativar clientes, querem permanecer, pois se sentem cuidados e valorizados.

O cuidar fica evidente nos primeiros passos dos ingressantes, sejam calouros ou transferidos. Se for verdade que a "primeira impressão é a que fica", há enorme esforço institucional para que isso aconteça. A primeira semana de aula é reservada apenas para esses alunos. Acontecem eventos de acolhida que englobam: o pronunciamento do Reitor, que explica os princípios filosóficos da instituição e o seu comprometimento com a formação acadêmica; atividades de integração, visando à descontração e socialização dos recémchegados; tour pelo campus, a fim de que os alunos conheçam a "sua" nova casa, nela se sintam bem e com vontade de permanecer. Ao longo das primeiras semanas de aulas, esse clima é mantido com a presença de pessoas disponibilizadas no pátio para atender as dúvidas dos ingressantes.

Estou muito impressionada com a atenção que recebi. $O$ que tenho a dizer é que minha vontade de cursar o [...] aumentou mais ainda. [...] Estou muito feliz!! Parabéns a todos que administram a [...]. Excelente trabalho.

Bem, estava meio insegura, pois vim através de transferência, e a turma já se conhece... espero ser tão bem recebida pela turma como fui pela facul, e realmente me dedicar, conhecer novas pessoas...e aproveitar os melhores anos de minha vida, q é cursar uma faculdade!!!hehe to mtooo animada...

A recepção aos calouros foi simplesmente ótima, estou me sentindo muito segura em voltar a estudar depois de tanto tempo longe, parabéns [...], e obrigada pelo carinho, espero q continue assim....rs...!!!!" (comentários dos alunos divulgados na rede social da IES em relação à acolhida).

A estrutura do campus e as ofertas de atividades fizeram com que muitos alunos aumentassem seu tempo de permanência, formando rodas de bate-papo e grupos de estudos 
para além dos momentos de aula, criando redes de afiliação. Acrescentamos que lembranças, percepções e pertencimentos dependem das relações de poder que os sujeitos experimentam em sua cultura. Esse pensamento conduz à noção de que toda experiência humana não é natural, ela é significada. Ou seja, nessa movimentação envolta por significados comuns, os sujeitos colocam em circulação valores quanto à instituição que frequentam e aos modos como ela administra o espaço e as relações sociais, engendrando modos de ver o ES, os cursos que realizam, como a EF, os docentes que os assistem, os modos de ser de determinada carreira profissional etc. Para Rocha (2000), o espaço delimita a distribuição das pessoas, permite ou interdita práticas sociais, valoriza e descarta artefatos, em suma, a arquitetura de uma instituição pode ser considerada uma forma silenciosa de ensino.

Com Foucault (2012), aprendemos que a arquitetura das instituições é capaz de disciplinar os corpos. No caso, uma disciplina menos incômoda, menos conflituosa e com mais liberdade, logo, com mais poder para regular o comportamento conveniente aos interesses institucionais e, quiçá, econômicos, políticos, culturais e sociais, enfim, globais. Na duplicidade entre intenções e estética, a racionalização do espaço produz efeitos de sentido sobre os sujeitos e potencializa certos modos de identificação com as condições impostas pelos discursos do mercado.

\section{PARA A CONVERSA PROSSEGUIR}

Neste artigo, procuramos realçar aspectos que não são considerados nas análises realizadas acerca dos currículos da formação inicial dos professores de EF, que, sem dúvida, operam representações e influem seus modos de ser.

Enquanto dispositivo do currículo, a racionalização do espaço parece funcionar como forma de pedagogia cultural que dá vida ao dia a dia da instituição. Mediante uma miríade de estratégias, que se renovam constantemente, tenta-se a construção de modos de influir e regular a maneira como seus sujeitos agem e se veem em seu interior e preparam-se para vida em sociedade. Ao fazer circular discursos, promover práticas, definir a organização do espaço e a distribuição do tempo, dirigir para determinadas finalidades as decisões administrativas, o currículo coloca em operação uma série de tecnologias que introduzem novas formas de regulação dos sujeitos e influenciam a constituição das identidades dos estudantes, dos professores, da EF e do ES. Enfim, são aspectos que constroem novas formas de subjetividade em uma cultura de consumo.

Ao relacionar a representação que o espaço físico do campus pode significar com as questões emergentes da reforma do ES, entendemos que a configuração de um lugar não apenas produz a sua identidade. Ela apresenta uma história social e política. E assim sendo, afeta de diversas formas alunos, gestores, colaboradores e visitantes. A racionalização do espaço funciona como eficiente mecanismo regulado por uma linguagem discursiva e uma não discursiva que impõem um jogo de verdade a esses indivíduos, objetivando-os, normatizando suas ações nesse espaço. Ao mesmo tempo, essas linguagens os subjetivam, pois os fazem falar de si mesmos e produzem uma verdade acerca de uma consciência de si (FOUCAULT, 2004).

Nessa operação, nota-se a concepção atual de transformação tanto do ES como do trabalho, pois é evidente que essa instituição procura romper com os padrões tradicionais de ambiente que marcaram tanto o ensino acadêmico como o próprio mundo do trabalho. 
O corolário necessário desse discurso é a rejeição de outro: o da conformação do homem à estrutura da sociedade. Ao que tudo indica, inserir sujeitos em ambientes sedutores e aprazíveis pode destituir o sentido de sofrimento e obediência que os velhos padrões sociais produziam nesse espaço social. Instaurar os sentidos de alegria, liberdade, direito, vontade individual, aliados ao discurso da qualidade total e da qualidade de vida, parece alimentar um novo sonho em que se vislumbra uma vida melhor. Nesse ambiente, estudo, trabalho e formas de socialização são ressignificados e o sujeito destes tempos é produzido.

A racionalização do espaço em análise é aqui compreendida como estratégia que cria afetos pela lógica de gerenciamento elaborada pelos mercados de consumo. É uma forma de pedagogia cultural capaz de ensinar uma única maneira de organizar, acolher, conviver, estar. Trata-se de mais uma tecnologia capaz de produzir uma nova identidade na contemporaneidade, qual seja, um sujeito afeito ao consumo, ao espetáculo, à volatilidade, e promover e validar em sua trajetória pessoal e profissional práticas com os mesmos sentidos, constituindo uma nova forma de pensar a cultura. Cabe agora pensarmos como isso se dá em outros espaços educativos.

\section{REFERÊNCIAS}

BALL, Stephen. Performatividade, privatização e o pós-estado do bem-estar. Educação e Sociedade, v. 25, n. 89, p. 1105-1126, set./dez. 2004. (Dossiê: Globalização e Educação: precarização do trabalho docente, 2).

BAUMAN, Zygmunt. Vida para consumo: a transformação das pessoas em mercadorias. Rio de Janeiro: Zahar, 2008.

BURBULES, Nicholas; TORRES, Carlos Alberto. Globalização e Educação: uma introdução. In: BURBULES, Nicholas; TORRES, Carlos Alberto. Globalização e educação. Porto Alegre: Artes Médicas, 2004. p.11-26

FOUCAULT, Michel. Soberania e disciplina. In: Microfísica do poder. Rio de Janeiro: Graal, 1992a. p. 179-191.

FOUCAULT, Michel. O nascimento do hospital. In: Microfísica do poder. Rio de Janeiro: Graal, 1992b. p. 99-111.

FOUCAULT, Michel. A ética do cuidado de si como prática de liberdade. In: Ditos e escritos V: ética, sexualidade, política. Rio de Janeiro: Forense Universitária, 2004. p. 264-287.

FOUCAULT, Michel. Segurança, território e população. São Paulo: Martins Fontes, 2008a.

FOUCAULT, Michel. 0 nascimento da biopolítica. São Paulo: Martins Fontes, 2008b.

FOUCAULT, Michel. Vigiar e punir: nascimento da prisão. Petrópolis: Vozes, 2012.

HALL, Stuart. A identidade cultural na pós-modernidade. Rio de Janeiro: DP\&A, 2003.

LIPOVETSKY, Gilles. O reino da hipercultura: cosmopolitismo e civilização ocidental. In: JUVIN, Hervé; LIPOVETSKY, Gilles. A globalização ocidental: controvérsias sobre cultura planetária. Barueri: Manole, 2012. p. 1-67 
LIPOVETSKY, Gilles; SERROY, Jean. A cultura-mundo: a resposta a uma sociedade desorientada. São Paulo: Companhia das Letras, 2011.

MOREIRA, Antônio Flávio Barbosa. Currículo, utopia e pós-modernidade. In: MOREIRA, Antônio Flávio Barbosa. (Org.) Currículo: questões atuais. Campinas: Papirus, 2006. P. 9-28.

NUNES, Mário Luiz Ferrari; NEIRA, Marcos Garcia. Processos de inclusão excludente presentes no Ensino Superior privado. Educação \& Realidade, v. 39, n. 4, p. 1209-1228, 2014.

POPKEWITZ, Thomaz S. História do currículo: regulação social e poder. In: SILVA, Tomaz Tadeu da. $O$ sujeito da educação: estudos foucaultianos. Petrópolis: Vozes, 1995. p 173-210.

ROCHA, Cristiane Famer. O espaço escolar em revista. In: COSTA, Marisa Vorraber. (Org.) Estudos culturais em educação: mídia, arquitetura, brinquedo, biologia, literatura, cinema... Porto Alegre: UFRGS Editora, 2000. p. 117-142.

SALES, Luís Carlos; PASSOS, Guiomar de Oliveira. As aparências não enganam: as representações sociais de qualidade suscitadas pelos prédios escolares. Revista Brasileira de Educação, v. 13, n. 38, p. 293-304, maio/ago. 2008.

VEIGA-NETO, Alfredo. Educação e governamentalidade neoliberal: novos dispositivos, novas subjetividades. In: PORTOCARRERO, Vera; CASTELO BRANCO, Guilherme (Org.) Retratos de Foucault. Rio de Janeiro: Nau, 2000. p 179-217.

VEIGA-NETO, Alfredo; SARAIVA, Karla. Educar como arte de governar. Currículo sem Fronteiras, v. 11, n. 1, p. 5-13, jan./jun. 2011. 